\title{
Pen Torch Transillumination: Difficult Venepuncture Made Easy: Reply
}

\author{
Elijah Zhengyang Cai ${ }^{1} \cdot$ Kalarani Sankaran ${ }^{2} \cdot$ Monica Tan $^{3} \cdot$ Yiong Huak Chan ${ }^{4} \cdot$ Thiam Chye Lim $^{5,6}$
}

Published online: 10 October 2017

(C) Société Internationale de Chirurgie 2017

Dear Sir,

Thank you for your comments.

All the patients recruited had venepuncture performed in daylight between $0800 \mathrm{H}$ and $1800 \mathrm{H}$ in a six-bedded open ward, except for a case that was performed at $2000 \mathrm{H}$.

Pen Torch Transillumination (PTI) functioned well in daylight, without the need to dim the lights to visualize the veins.
No patient required central venous catheterization or venous cut-down due to inability to obtain venous access.

We used pen torches (Penlite-LP212, Energizer, Missouri, USA) that utilize light-emitting diode (LED). These generate less heat compared to incandescent or halogen bulbs.

No thermal burns or complaints regarding discomfort due to heat from the torches were encountered.

Elijah Zhengyang Cai

elijah_cai@nuhs.edu.sg

1 General Surgery, National University Health System, Singapore, Singapore

2 Department of Nursing, National University Health System, Singapore, Singapore

3 Department of Anesthesiology, Singhealth, Singapore, Singapore

4 Biostatistics Unit, Yong Loo Lin School of Medicine, National University of Singapore, Singapore, Singapore

5 Yong Loo Lin School of Medicine, National University of Singapore, Singapore, Singapore

6 Division of Plastic, Aesthetic and Reconstructive Surgery, University Surgical Cluster, National University Health System, Singapore, Singapore 